\title{
Design and Implementation of an Air Quality Testing System Based on STC12C5A
}

\author{
Fenglong $\mathrm{Wu}^{1}$, Fangmei Liu $^{2 *}$, Yuan Feng ${ }^{2}$, Zengyu Cai ${ }^{2}$ \\ ${ }^{1}$ College of Software Engineering, Zhengzhou University of Light Industry, \\ Zhengzhou 450002, China \\ ${ }^{2}$ College of Computer and Communication Engineering, Zhengzhou University of Light Industry, \\ Zhengzhou 450002, China \\ *Email: fangmei_liu21@126.com
}

Received: February 22, 2021. Revised: July 30, 2021. Accepted: August 22, 2021. Published: August 25, 2021.

\begin{abstract}
Indoor air quality and human health have proven to be related, but for home environment air quality detection system equipment accuracy is not high problem. This paper designs an air quality detection system that effectively handles the information of indoor air pollution. The microcontroller unit (MCU) STC12C5A was taken as the core to realize the detection and display of particulate matter (PM) 2.5 concentration, temperature, and humidity. Compared with the measurements by standard instruments, our system was proved effective through tests: the relative error of PM2.5 concentration was smaller than $3 \mu \mathrm{g} / \mathrm{m}^{3}$; the temperature error was within $1^{\circ} \mathrm{C}$; the humidity error was below $5 \%$ relative humidity $(\mathrm{RH})$. This research provides an effective way to detect indoor air quality. The results of this paper are suitable for home environment and have a good application prospect.
\end{abstract}

Keywords-Air quality; particulate matter (PM) 2.5; temperature and humidity: STC12C5A.

\section{INTRODUCTION}

$\mathrm{M}$ ANY public places belong to indoor environment, such as housing, offices, public transit, and hotels. Statistics show that at least $80 \%$ of our life is spent indoors [1]. Thus, indoor air quality is closely related to human health [2].

Recent years has seen a continuous deterioration of environment in many regions. For example, the frequent occurrence of smog weather poses a threat to our health. As the main component of smog [3-5], particulate matter (PM) 2.5 becomes an invisible killer of human health, and attracts attention from around the world.

PM2.5 refers to the particulate matter whose aerodynamic equivalent diameter is below than $2.5 \mu \mathrm{m}$. The main sources of PM2.5 include combustion of fossil fuels and exhaust emissions of vehicles $[6,7]$. PM2.5 can enter our body through respiratory tract, causing cardiovascular and respiratory diseases. Therefore, it is very meaningful to explore new ways to detect PM2.5 [8-12].

To realize rapid detection of indoor air quality, this paper designs an air quality detection system, which captures and displays the PM2.5 concentration, temperature, and humidity of the air, and activates alarms if any of these parameters violate the preset alarm thresholds.

\section{OVERALL DESIGN}

Figure 1 provides the block diagram of the overall design for our system. Taking microcontroller unit (MCU) STC12C5A as the core, our system consists of a temperature and humidity sensor DHT11, a PM2.5 sensor GP2Y1051AUOF, an audiovisual alarm (buzzer), a liquid crystal display (LCD), and a button setting module, to name but a few.

During the operation, the operator can set the upper limit of PM2.5 concentration, as well as the upper and lower limits of temperature and humidity by pressing buttons. The ambient temperature, humidity, and PM2.5 concentration are collected by relevant sensors, and displayed on the LCD. Then, the collected data are compared with the preset values of the microcontroller unit (MCU), and the light-emitting diode (LED) display will show different colors, depending on whether the data are above or below the thresholds. If the data violate the threshold, the buzzer will give off an alarm. 


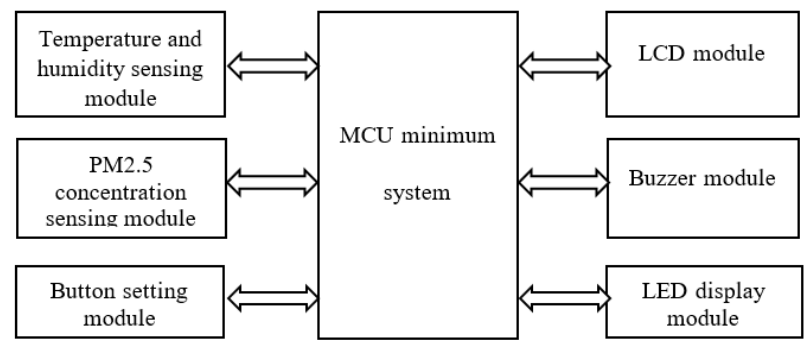

Fig. 1 overall design of our system

\section{HARDWARE DESIGN}

The core of hardware design is the STC12C5A minimum system. Meanwhile, the peripheral circuits include temperature and humidity sensing module, PM2.5 concentration sensing module, button setting module, LCD module, buzzer module, and LED display module.

\section{A. Minimum system circuit}

STC12C5A minimum system consists of three parts: power supply, reset, and crystal oscillator. Specifically, the power circuit adopts the $5 \mathrm{~V}$ universal serial bus (USB) power supply port; the reset circuit is made up of $10 \mathrm{~K}$ resistors and a $10 \mu \mathrm{F}$ capacitor, When the RST foot is added with a high level lasting more than two machine cycles, the SCM begins to reset; the crystal oscillator circuit encompasses a $11.0592 \mathrm{M}$ crystal oscillator and a $30 \mathrm{pF}$ capacitor, providing reference frequency for other circuits. In addition, because of the single chip P0 port no pull resistance, so here access to the $10 \mathrm{~K}$ exclusion resistance, the PO port as the LCD data port. The circuit diagram of the minimum system is shown in Figure 2.

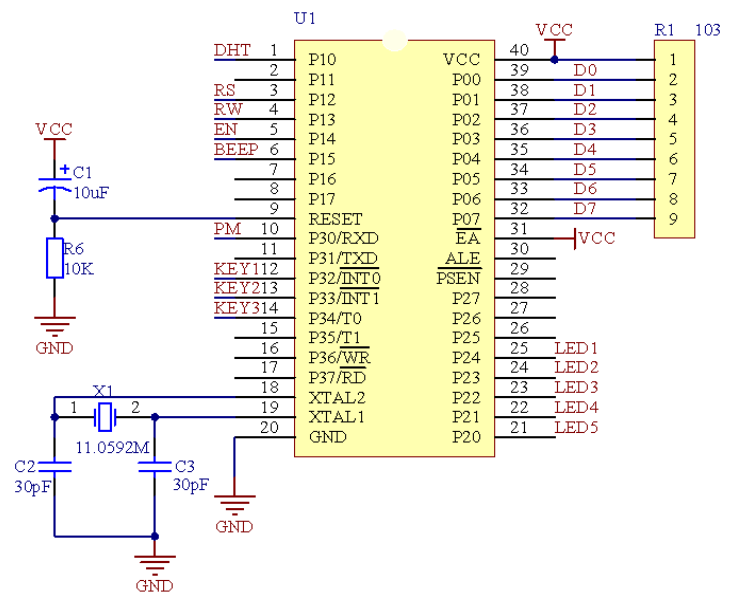

Fig. 2 circuit diagram of the minimum system

\section{B. DHT11 sensor circuit}

DHT11 is a temperature and humidity sensor that outputs calibrated digital signals. The stability and reliability of the sensor are guaranteed by resistance humidity, negative temperature coefficient (NTC) temperature measurement components, and digital module acquisition technology. The sensor can adapt to various harsh environments, thanks to its good quality and strong anti-interference ability [13]. The DHT11 sensor is packaged with 4-pin single row for easy connection, and can also be packaged in special form according to user's request. Figure 3 presents a photo of the DHT11 sensor.

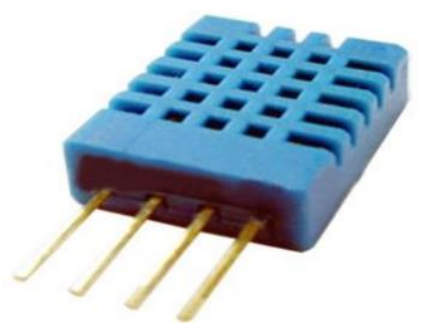

Fig. 3 DHT11 sensor

Once the system is powered on, the MCU will send out a signal. The DHT11 will make a mode transition after detecting that signal. Then, the sensor will send a response signal and 40 bits of data, kicking off the acquisition of temperature and humidity data. After acquiring the data, the high speed mode will switch to the low power mode [14]. The communication between DHT11 and MCU is illustrated in Figure 4.

The bus is originally at a high voltage. When the communication between MCU and DHT11 begins, the MCU sets the bus voltage from high to low. Then, the DHT sends out a low level signal after detecting MCU's signal. Next, the MCU will pull up bus voltage and wait for the response from DHT. 


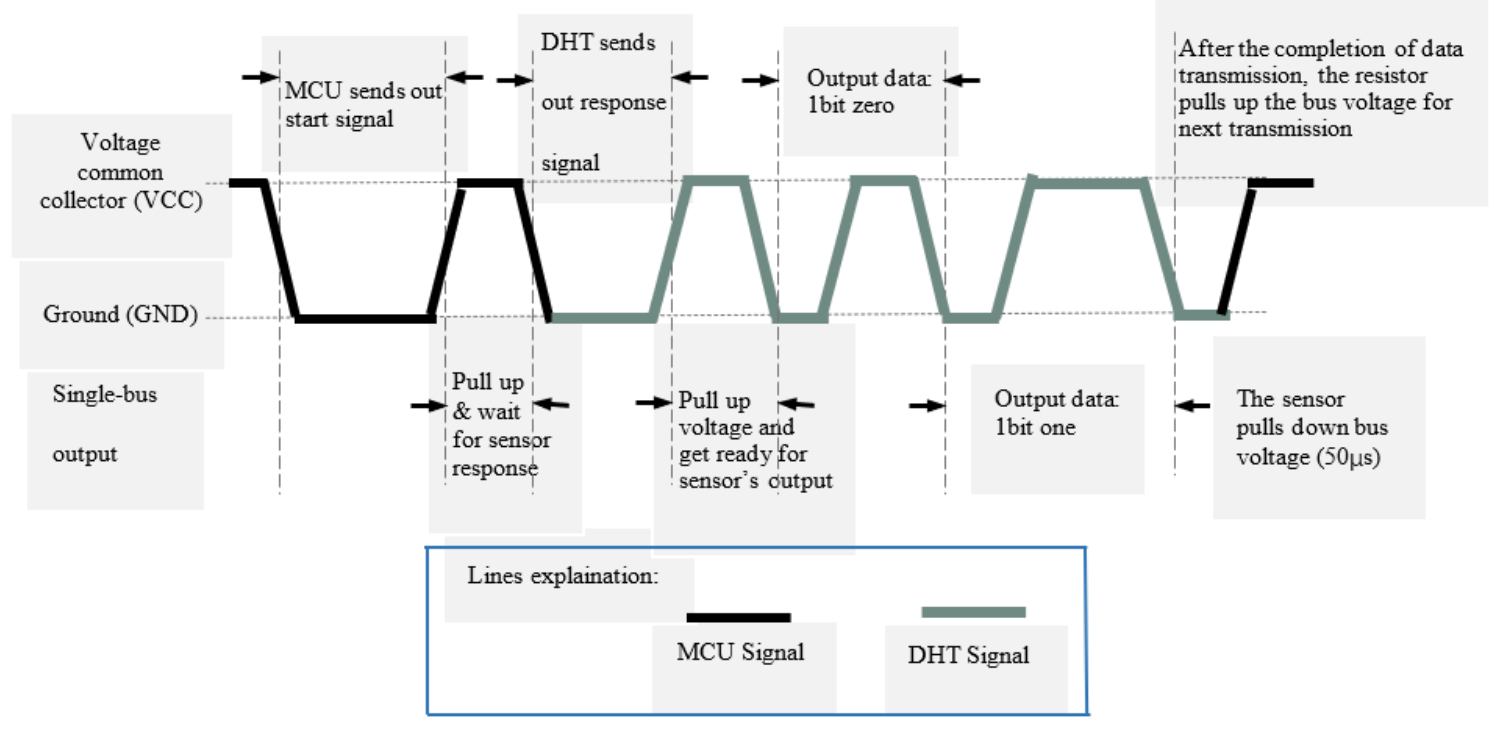

Fig. 4 communication between DHT11 and MCU

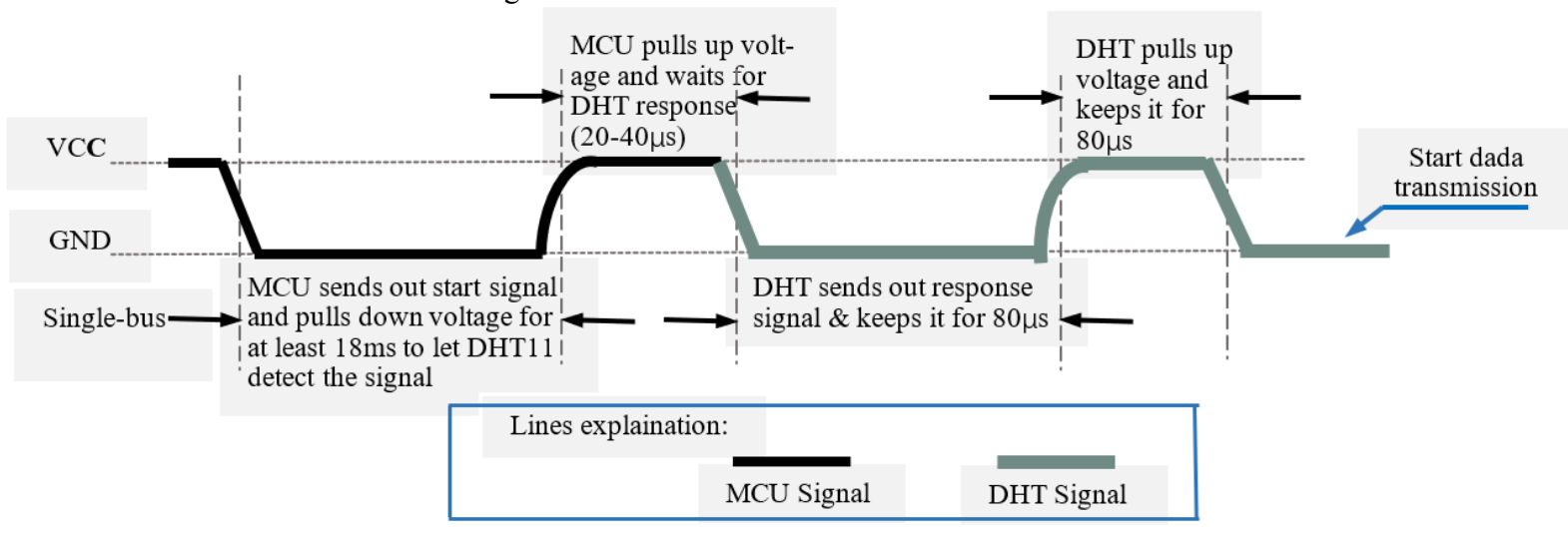

Fig. 5 initialization of the DHT11-MCU communication

\section{PM2.5 sensing module}

It adopts GP2Y1051AUOF (Sharp, Japan), a powerful dust sensor that detects particles above $0.03 \mu \mathrm{m}$. With high smoke sensitivity, the sensor is embedded with photoelectric and infrared LEDs. Capable of pinpointing the reflected light of dust, GP2Y1051AUOF is widely adopted in air purification systems.

The core of the GP2Y1051AUOF is the LED light source. Light is emitted along the optical axis of LED. When the air is clean, the LED light is not received by photodiode (PD), and the output voltage is low. And if there is dust particles in the air, when the dust particles by sensors in the middle of the round hole, because of the scattering, LED light source, light is part of the photodiode PD detected, therefore has the voltage output, and with the increase of concentration of dust particles, the more light scattering, sensors, the higher the voltage value of the final output. When the air contains dust particles, the voltage value is outputted [15]. The output voltage is positively correlated with the concentration of dust particles. Figure 6 shows the structure of the GP2Y1051AUOF.

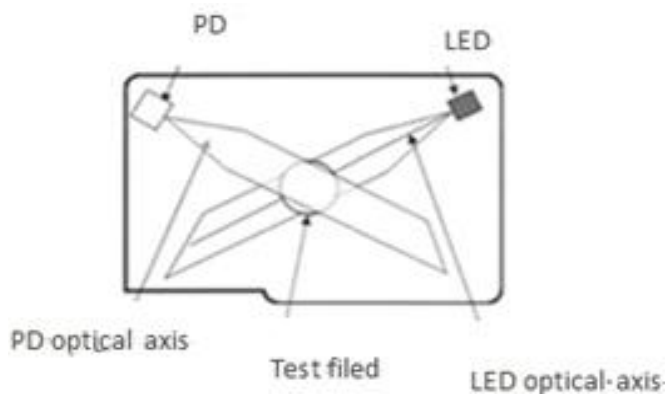

Fig. 6 PM2.5 sensor structure

The data are transmitted through the serial port of the sensor and MCU at the baud rate of 2,400 bit/s. In total, there are 7 bits transmitted at an interval of $10 \mathrm{~ms}$. Figure 7 shows the format of data during the transmission. 


\begin{tabular}{|c|c|c|c|c|c|c|}
\hline Start bit & $\operatorname{Vout}(\mathrm{H})$ & $\operatorname{Vout}(\mathrm{L})$ & Vref(H) & $\operatorname{Vout}(L)$ & Check bit & End bit \\
\hline 0xaa & as: $0 \times 01$ & as: $0 \times 3 a$ & as: $0 \times 00$ & as: $0 \times 7 a$ & as:0xd0 & as:0xff \\
\hline
\end{tabular}

Fig. 7 format of transmitted data

Note that check bit $=\operatorname{Vout}(\mathrm{H})+\operatorname{Vout}(\mathrm{L})+\operatorname{Vref}(\mathrm{H})+\operatorname{Vref}(\mathrm{L})$

where, $\operatorname{Vout}=(\operatorname{Vout}(\mathrm{H}) * 256+\operatorname{Vout}(\mathrm{L})) / 1,024 * 5$.

The PM2.5 sensing module is connected to GND and VCC. The transmit (TXD) pin is coupled with the $\mathrm{P} 30$ pin of the MCU for data transmission. The circuit diagram of the PM2.5 sensing module is shown in Figure 8.

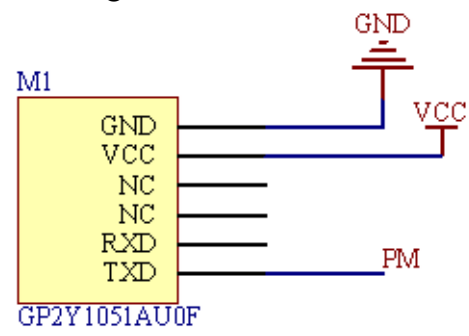

Fig. 8 circuit diagram of PM2.5 sensing module

\section{LCD circuit}

Our system uses a 1602 LCD that can intuitively express texts, graphics, symbols, and other contents, the operating voltage is between 4.5 and $5.5 \mathrm{~V} .1602$ can display 16 characters per line, a total of two lines. There are two types of dot matrix, each of which can display a character. The working principle of liquid crystal display (LCD) is that under the action of electric field, the liquid crystal molecules will have chemical reaction, and the arrangement of molecules will change, resulting in the electro-optic effect, and the LCD will display all kinds of contents. As shown in Figure 9, D0 to D7 of the LCD module are connected to P0 port of the MCU; VI pin is connected to potentiometer for contrast adjustment.

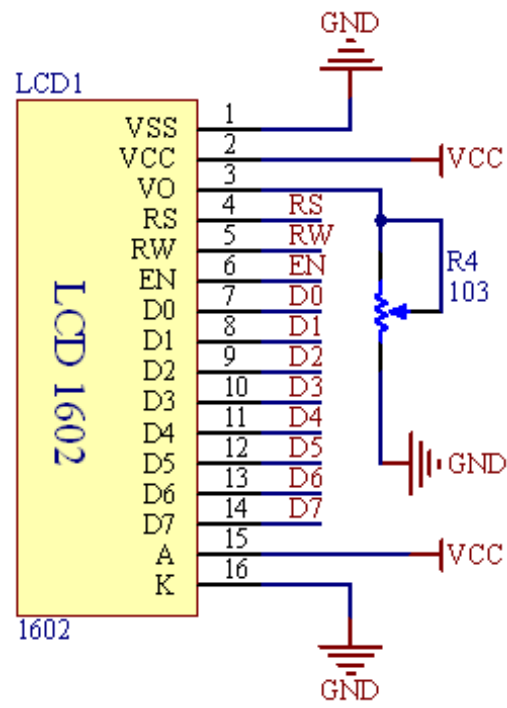

Fig. 9 circuit diagram of LCD module

\section{E. Buzzer module}

The buzzer module serves as an alarm system. In this paper, the active buzzer can directly output the level, the single chip microcomputer does not need to continuously send out high and low levels, only need to output high or low levels. In this way, the program design of SCM will be greatly simplified. As shown in Figure 10, the alarm system will start and give off an alarm, when the collected data violate the preset thresholds.

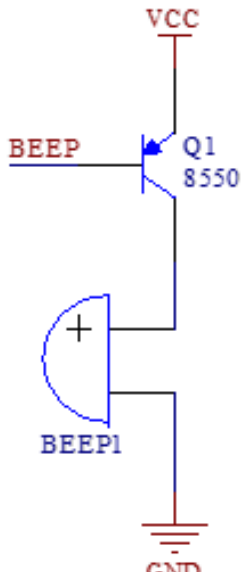

Fig. 10 circuit diagram of buzzer module

\section{F. Button setting module}

The parameters required by the MCU are set on a keyboard, which offers three buttons, namely, "Settings", "Plus", and "Subtract". The lower limit of temperature, upper limit of temperature, lower limit of humidity, upper limit of humidity, and upper limit of PM2.5 concentration can be set by pressing the "Settings" button once, twice, three times, four times, and five times, respectively, wait about 0.5 seconds, the system will be set up successfully. The upper and lower limits can be increased or decreased by pressing "Plus" and "Subtract", respectively. After setting a limit, the "Settings" button should be pressed again, and the limit will come into effect after $0.5 \mathrm{~s}$. Figure 11 shows the circuit diagram of button setting module.

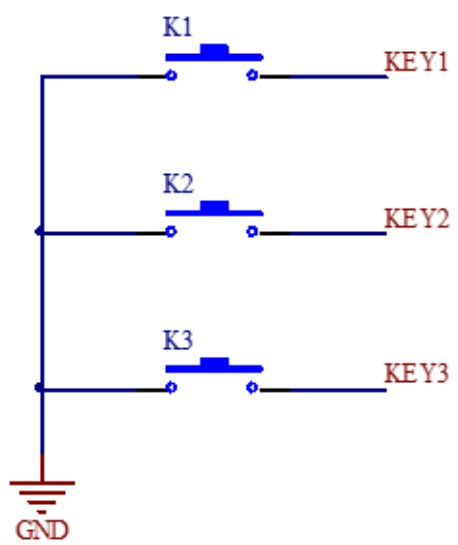

Fig. 11 circuit diagram of button setting module 


\section{G. LED display circuit}

LED lights are often used as circuit indicators. The LED display circuit in this paper uses 5 LED lamps. When the circuit starts to work, the upper limit and lower limit of temperature and humidity and the upper limit of PM2.5 concentration need to be set first. After that, if the external environment changes, when the temperature and humidity or PM2.5 concentration is not within the range set by the system, the corresponding LED indicator light will be lit accordingly, and they will not affect each other. The circuit connection is shown in Figure 12.

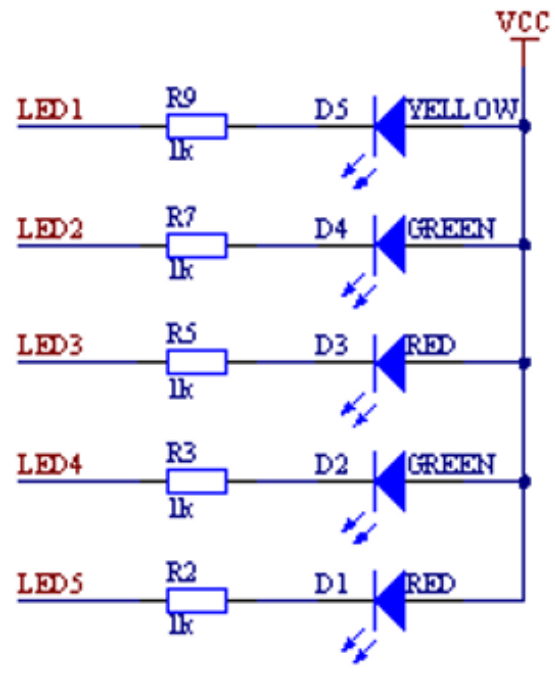

Fig. 12 circuit diagram of LED display circuit

\section{SOFTWARE DESIGN}

\section{A. 1602 LCD programming}

The liquid crystal display part adopts LCD1602. First of all, before the LCD begins to display, it must first determine a position, indicating where to show; Then, the liquid crystal in the display of content is a bit by bit, when each display a string of characters or a number, only need to complete a positioning at the beginning, after each display of a character, the liquid crystal will automatically jump to the next position, do not need to reposition each character. Figure 13 shows the workflow of the 1602 LCD program.

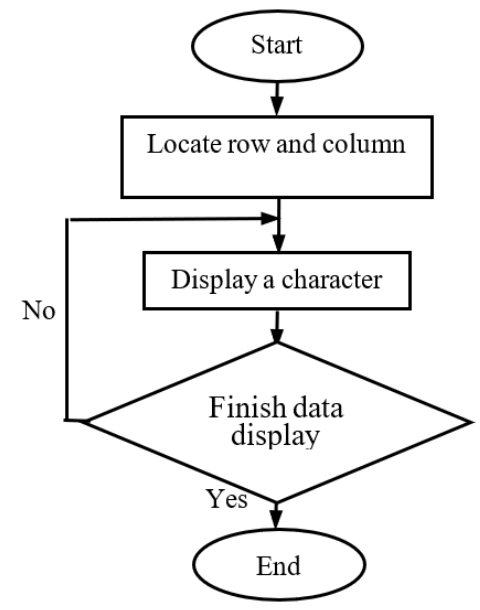

Fig. 13 flow chart of 1602 LCD

\section{B. DHT11 sensor programming}

Before reading temperature and humidity data, the MCU must send a start signal to the DHT11 sensor. Upon receiving the signal, the sensor will make a mode transition, and start to measure the required data. Then, humidity, temperature, and check bits will be sent to MCU in sequence. After that, the MCU checks if the data are correctly transmitted. If there is any error, the data will be directly discarded; otherwise, the data will be saved and sent to the LCD. Figure 14 shows the workflow of DHT11 sensor.
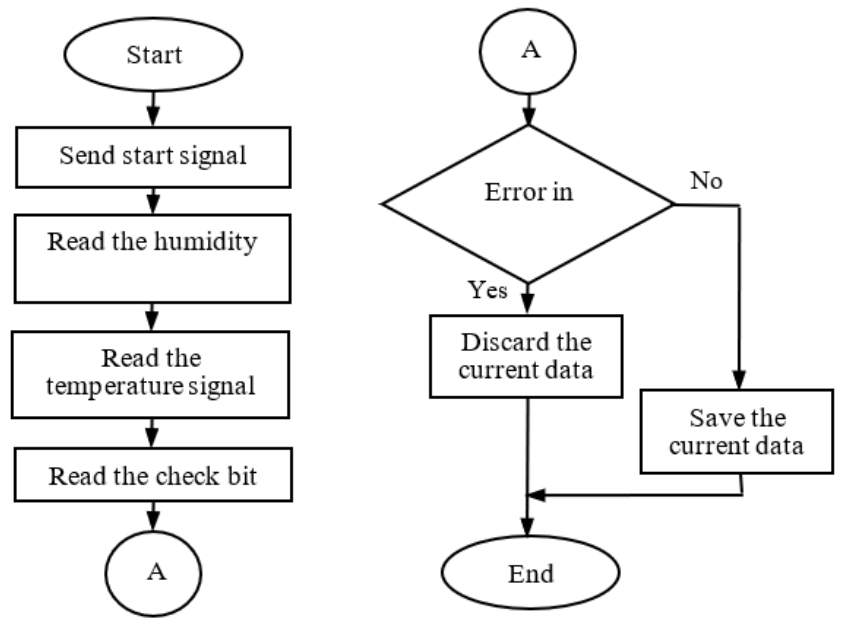

Fig. 14 flow chart of DHT11 sensor

\section{General program}

The general program of our air quality detection system includes MCU initialization, data reading, data processing, result display, and alarm. The general program was written in the Keil $\mu$ Vision IDE development system. The various functions were realized in C-language. The overall program needs to achieve the functions are: the first is to start the function of the LCD display, display content, alarm value and serial port initialization; Then, the system will receive the temperature and humidity data signal collected by the DHT11 sensor, and read the temperature and humidity measurement results for display; After receiving the data signal collected by 
the PM2.5 sensor and reading the PM2.5 measurement results for display; Then, the program will judge whether the temperature, humidity and PM2.5 concentration just read are within the alarm range set previously. If they exceed the set range, an acousto-optic alarm will be started. Trigger to determine whether the setting button is pressed, if yes, it will enter the alarm range setting; There is a brief delay, at which point it completes one cycle and begins the next cycle. Figure 15 shows the workflow of ours system.

\section{System simulation}

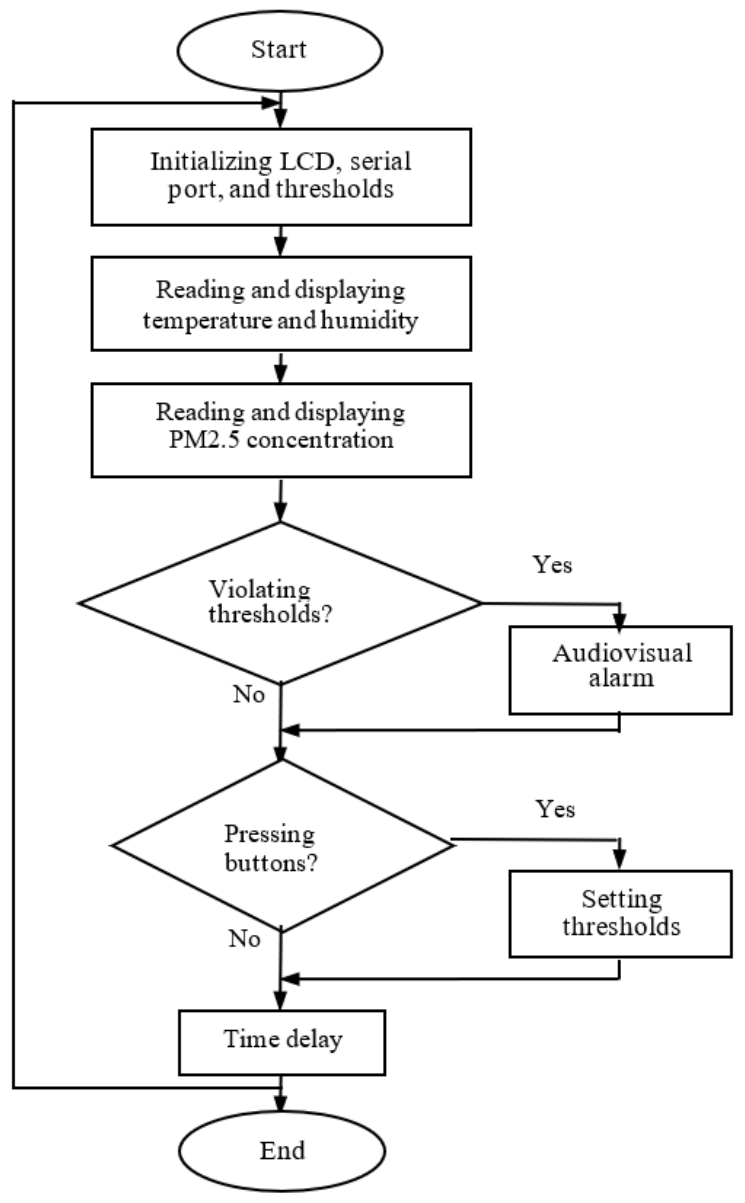

Fig. 15 flow chart of our system

Our system was simulated on Proteus. The simulation program (Figure 16) was downloaded into the simulation circuit after the completion of the overall circuit design. However, Proteus does not have any components of PM2.5 sensing. Thus, a virtual serial port driver and STC in-system programming (ISP) software were selected to generate PM2.5 concentration signals. During the simulation, once the $\mathrm{MCU}$ received abnormal data, the system issued an alarm and turned on the corresponding LED.

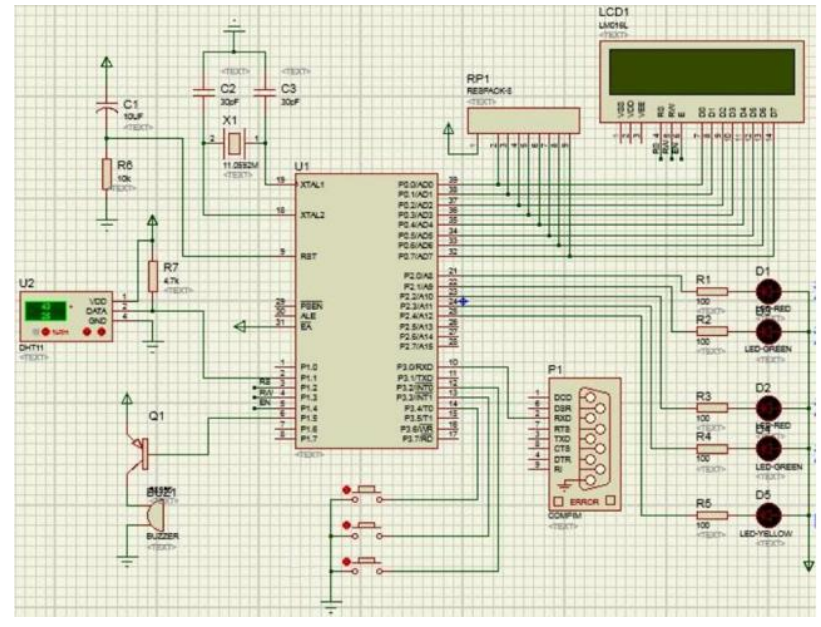

Fig. 16 simulation diagram

\section{System Test}

To verify the accuracy and function of our system, the temperature, humidity, and PM2.5 measured by our system were compared with the data captured by standard instruments. The contrastive standard instruments include an SDL307 PM2.5 mass spectrometer to measure the concentration of PM2.5, and a TASI-622A temperature and humidity meter to measure the temperature and humidity. Table 1 compares the data of our system with those of the standard instruments at 9 time points in an indoor environment test. It can be seen that the relative error of PM2.5 concentration was smaller than $3 \mu \mathrm{g} / \mathrm{m}^{3}$; the temperature error was within $1^{\circ} \mathrm{C}$; the humidity error was below $5 \%$ relative humidity $(\mathrm{RH})$. The results demonstrate the high accuracy of our system.

Besides the accuracy test, a series of functional tests were carried out to verify the functions of our system. Before the test, the lower and upper limits of temperature were set to $18^{\circ} \mathrm{C}$ and $34^{\circ} \mathrm{C}$, respectively; the lower and upper limits of humidity were set to $30 \% \mathrm{RH}$ and $55 \% \mathrm{RH}$, respectively; the limit of PM2.5 concentration was set to $30 \mu \mathrm{g} / \mathrm{m}^{3}$.

Then, six functional tests were organized by control variates method. Each time, a single variable among temperature, humidity, and PM2.5 concentration was placed in alarm range. Specifically, the temperature was adjusted to $16^{\circ} \mathrm{C}$ and $35^{\circ} \mathrm{C}$ respectively by an air conditioner; the humidity was adjusted to $25 \% \mathrm{RH}$ and $60 \% \mathrm{RH}$ respectively by a humidifier and a drier; the PM2.5 was generated by passing pulverized coal through a vibrating screen, making the local PM2.5 concentration reach $35 \mu \mathrm{g} / \mathrm{m}^{3}$. The results of functional tests (Table 2) show that our system issued alarmed whenever temperature, humidity, or PM2.5 concentration violated the thresholds.

Table 1. Results of indoor environment test

\begin{tabular}{|c|c|c|c|c|c|c|}
\hline $\begin{array}{c}\text { Time } \\
\text { points }\end{array}$ & $\begin{array}{c}\text { Measured } \\
\text { PM2.5 } \\
\text { concentration }\end{array}$ & $\begin{array}{c}\text { Standard PM2.5 } \\
\text { concentration }\end{array}$ & $\begin{array}{c}\text { Measured } \\
\text { temperature }\end{array}$ & $\begin{array}{c}\text { Standard } \\
\text { temperature }\end{array}$ & $\begin{array}{c}\text { Measured } \\
\text { humidity }\end{array}$ & $\begin{array}{c}\text { Standard } \\
\text { humidity }\end{array}$ \\
\hline $6: 00$ & $8 \mu \mathrm{g} / \mathrm{m}^{3}$ & $6 \mu \mathrm{g} / \mathrm{m}^{3}$ & $20^{\circ} \mathrm{C}$ & $20^{\circ} \mathrm{C}$ & $52 \% \mathrm{RH}$ & $51 \% \mathrm{RH}$ \\
\hline
\end{tabular}


INTERNATIONAL JOURNAL OF CIRCUITS, SYSTEMS AND SIGNAL PROCESSING

\begin{tabular}{|c|c|c|c|c|c|}
\hline $8: 00$ & $9 \mu \mathrm{g} / \mathrm{m}^{3}$ & $11 \mu \mathrm{g} / \mathrm{m}^{3}$ & $24^{\circ} \mathrm{C}$ & $25^{\circ} \mathrm{C}$ & $49 \% \mathrm{RH}$ \\
\hline $10: 00$ & $7 \mu \mathrm{g} / \mathrm{m}^{3}$ & $10 \mu \mathrm{g} / \mathrm{m}^{3}$ & $26^{\circ} \mathrm{C}$ & $26^{\circ} \mathrm{C}$ & $45 \% \mathrm{RH}$ \\
\hline $12: 00$ & $9 \mu \mathrm{g} / \mathrm{m}^{3}$ & $9 \mu \mathrm{g} / \mathrm{m}^{3}$ & $26^{\circ} \mathrm{C}$ & $26^{\circ} \mathrm{C}$ & $45 \% \mathrm{RH}$ \\
\hline $14: 00$ & $10 \mu \mathrm{g} / \mathrm{m}^{3}$ & $8 \mu \mathrm{g} / \mathrm{m}^{3}$ & $26^{\circ} \mathrm{C}$ & $27^{\circ} \mathrm{C}$ & $43 \% \mathrm{RH}$ \\
\hline $16: 00$ & $11 \mu \mathrm{g} / \mathrm{m}^{3}$ & $12 \mu \mathrm{g} / \mathrm{m}^{3}$ & $24^{\circ} \mathrm{C}$ & $23^{\circ} \mathrm{C}$ & $45 \% \mathrm{RH}$ \\
\hline $18: 00$ & $15 \mu \mathrm{g} / \mathrm{m}^{3}$ & $18 \mu \mathrm{g} / \mathrm{m}^{3}$ & $23^{\circ} \mathrm{C}$ & $22^{\circ} \mathrm{C}$ & $43 \% \mathrm{RH}$ \\
\hline $20: 00$ & $13 \mu \mathrm{g} / \mathrm{m}^{3}$ & $13 \mu \mathrm{g} / \mathrm{m}^{3}$ & $20^{\circ} \mathrm{C}$ & $19^{\circ} \mathrm{C}$ & $44 \% \mathrm{RH}$ \\
\hline $22: 00$ & $13 \mu \mathrm{g} / \mathrm{m}^{3}$ & $15 \mu \mathrm{g} / \mathrm{m}^{3}$ & $17^{\circ} \mathrm{C}$ & $16^{\circ} \mathrm{C}$ & $55 \% \mathrm{RH}$ \\
\hline
\end{tabular}

Table 2. Results of functional tests.

\begin{tabular}{|l|l|l|l|}
\hline Thresholds & Measured results & LEDs & Buzzer \\
\hline $17^{\circ} \mathrm{C}$ & $17^{\circ} \mathrm{C}$ & LED1 & On \\
\hline $34^{\circ} \mathrm{C}$ & $35^{\circ} \mathrm{C}$ & LED2 & On \\
\hline $30 \% \mathrm{RH}$ & $25 \% \mathrm{RH}$ & LED3 & On \\
\hline $55 \% \mathrm{RH}$ & $60 \% \mathrm{RH}$ & LED4 & On \\
\hline $30 \mu \mathrm{g} / \mathrm{m}^{3}$ & $35 \mu \mathrm{g} / \mathrm{m}^{3}$ & LED5 & On \\
\hline
\end{tabular}

\section{CONCLUSIONS}

This paper designs an STC12C5A-centered indoor air quality detection system, and proves that the system can detect and display PM2.5 concentration, temperature, and humidity of the indoor air. During the verification tests, whenever the measured data violated the thresholds, the system could issue an alarm with the buzzer and corresponding LED light; the relative error of PM2.5 concentration was smaller than $3 \mu \mathrm{g} / \mathrm{m}^{3}$; the temperature error was within $1^{\circ} \mathrm{C}$; the humidity error was below $5 \%$ RH. In addition, our system boasts a simple circuit structure, convenience in operation, and broad application prospects. Overall, our research provides a suitable way to measure the air quality in indoor environments. This system can only detect PM2.5, and has no function of detecting formaldehyde, Benben and other common harmful gases in home. Adding harmful gas detection function will be the focus of our next research.

\section{References}

[1] J. Li, "Design of air quality automatic measurement and control system based on single chip microcomputer," Electronic Test, pp. 26-37, 2017.

[2] C. Patko, I. Patko, Z. Pasztory, "Indoor Air Quality Testing in Low-Energy Wooden Houses: Measurement of Formaldehyde and VOC-s," Acta Polytechnica Hungarica, Vol. 10, No. 8, pp. 105-116, 2013.

[3] C. M. Kang, H. S. Lee, B. W. Kang, S. K. Lee, Y. Sunwoo, "Chemical characteristics of acidic gas pollutants and PM2. 5 species during hazy episodes in Seoul, South Korea," Atmospheric Environment, Vol. 38, No. 28, pp. 4749-4760, 2004. http://dx.doi.org/10.1016/j.atmosenv.2004.05.007

[4] M. Du, N. Liang, "Observations of atmospheric particulate matters and its local environmental effects in Japan," WSEAS Transactions on Environment and Development, Vol. 15, No. 1, pp. 176-181, 2019.

[5] R. Sahu, A. Nagal, K. K. Dixit, H. Unnibhavi, S. Mantravadi, S. Nair, Y. Simmhan, "Robust statistical calibration and characterization of portable low-cost air quality monitoring sensors to quantify real-time $\mathrm{O} 3$ and NO2 concentrations in diverse environments,"
Atmospheric Measurement Techniques, Vol. 14, No. 1, pp. 37-52, 2021.

[6] D. Martuzevicius, S. A. Grinshpun, T. Lee, S. Hu, P. Biswas, T. Reponen, G. LeMasters, "Traffic-related PM2. 5 aerosol in residential houses located near major highways: Indoor versus outdoor concentrations,"Atmospheric Environment, Vol. 42, No. 27, pp. 6575-6585, 2008.

[7] C. Buehler, F. Xiong, M. L. Zamora, "Stationary and portable multipollutant monitors for high-spatiotemporal-resolution air quality studies including online calibration," Atmospheric Measurement Techniques, Vol. 14, No. 2, pp. 995-1013, 2021.

[8] Y. Wang, C. Jia, J. Tao, L. Zhang, X. Liang, J. Ma, H. Gao, T. Huang, K. Zhang, "Chemical characterization and source apportionment of PM2. 5 in a semi-arid and petrochemical-industrialized city, Northwest China," Science of the Total Environment, Vol. 573, pp. 1031-1040, 2016.

[9] Z. Liu Z, G. Wang, L. Zhao, "Multi-points indoor air quality monitoring based on Internet of Things," IEEE Access, Vol. 99, pp. 1-1, 2021.

[10]P. Mocová, J. Mohelníková, "Indoor Climate Performance in a Renovated School Building," Energies, Vol. 14, No. 10, pp. 2827, 2021.

[11] I. Wardana, J. W. Gardner, S. A. Fahmy, “Optimising Deep Learning at the Edge for Accurate Hourly Air Quality Prediction," Sensors, Vol. 21, No. 4, pp. 1064, 2021.

[12]Z. A. Qi, T. C. Wang, G. J. Song, W. S. Hu. X. Li, Z. F. Zhang, "Deep Air Learning: Interpolation, Prediction, and Feature Analysis of Fine-Grained Air Quality," IEEE Transactions on Knowledge and Data Engineering, Vol. 30, No. 12, pp. 2285-2297, 2018.

[13]Z. R. Li, Q. C. Shen, "The Design of Intelligent Home PM2. 5 Environment Detector," Electronics World, No. 17, 2017.

[14] O. López-Ortega, F. Castro-Espinoza, O. Pérez-Cortés, "An intelligent multi-agent system to create and classify fractal music," Computing, Vol. 100, No. 7, pp. 671-688, 2018.

[15] C. D. Pollman, T. M. Lee, W. J. Andrews, L. A. Sacks, S. A. Gherini, R. K. Munson, "Preliminary analysis of the hydrologic and geochemical controls on acid- neutralizing capacity in two acidic seepage lakes in Florida," Water Resources Research, Vol. 27, No. 9, pp. 2321-2335, 1991.

Fenglong Wu, male, born in October 1976 in Henan, received his master degree in computer application technology from Zhengzhou University of Light Industry., Zhengzhou, China, in 
2000. He is a lecturer at Zhengzhou University of Light Industry, Zhengzhou, China. His research interests include data processing, machine learning and network security.

Fangmei Liu, female, born in February 1981 in Hunan, Master's degree, associate professor, lecturer in software of Zhengzhou University of Light Industry. Research interests: Information integration, artificial intelligence, etc. Having been engaged in teaching work for a long term, and have taught several courses including Operating system, Data structure, and so on. Meanwhile, I have published sixteen academic papers and two patents.

Yuan Feng, female, born in June 1979 in Henan, received her master degree in communication and information system from Chongqing University of Posts and Telecommunications, Chongqing, China, in 2006. She is a professor at Zhengzhou University of Light Industry, Zhengzhou, China. Her research interests include Embedded system and Communication.
Zengyu Cai, male, born in August 1980 in Henan, received his master degree in computer application technology from Northeast Normal University, Changchun, China, in 2006. He is a professor at Zhengzhou University of Light Industry, Zhengzhou, China. His research interests include trusted computing, plan recognition and information security.

\section{Creative Commons Attribution License 4.0 (Attribution 4.0 International, CC BY 4.0)}

This article is published under the terms of the Creative Commons Attribution License 4.0

https://creativecommons.org/licenses/by/4.0/deed.en_US 